\title{
Adoção: Práticas Jurídicas e Sociais no Império Luso-Brasileiro (XVIII-XIX) ${ }^{1}$
}

Alessandra Zorzetto MORENO •

Resumo: Nesse artigo, primeiramente, realizamos um histórico das interpretações jurídicas e historiográficas em torno da temática da adoção na sociedade luso-brasileira, no período anterior ao século XX. Em seguida, analisamos documentação inédita na historiografia representada por cartas e processos de adoção procurando entender as práticas sociais de incorporação sociofamiliar de filhos alheios.

Palavras-chave: Adoção; Legislação luso-brasileira; Transmissão de bens; Direito Romano.

\section{Adoção: abordagens jurídicas e historiográficas}

\begin{abstract}
Algumas vezes também, famílias honestas, privadas de filhos, procuram para sua companhia um enjeitado, a quem educam, adotam e legam seus bens; e este ser infeliz que parecia votado ao abandono, à miséria chega a ter o gozo de uma fortuna inesperada....

Barão de Gerando, Algumas considerações sobre os expostos - fragmentos da obra, 1843, p. 103. ${ }^{2}$
\end{abstract}

- Doutora em História Cultural pelo IFCH/UNICAMP. Pesquisadora vinculada ao projeto temático USP/FAPESP: O Império Português na Dimensão do Atlântico Sul: estruturas e dinâmicas do Antigo Sistema Colonial (coordenado pela Prof ${ }^{\mathrm{a}} \mathrm{D}^{\mathrm{a}}$ Laura de Mello e Souza) - Faculdade de Filosofia, Letras e Ciências Humanas - Universidade de São Paulo USP - 05508-900 - São Paulo - SP - Brasil. E-mail: afzbr@yahoo.com.br 
Segundo dados recentes, $63 \%$ dos brasileiros que praticam a adoção - legal ou informalmente - são motivados pela ausência de filhos biológicos. Nos grupos sociais com maior renda e escolaridade, os índices são mais expressivos revelando que $74 \%$ adotam devido à ausência de prole. Uma vez que as crianças e jovens disponíveis à adoção são oriundos das camadas populares e que $76 \%$ das pessoas mais favorecidas economicamente optam pela adoção legalizada, percebemos fortes indícios de que a adoção, atualmente, implica em mobilidade social para os adotados. Nesses casos, ela poderia se revestir de uma áurea romanceada bem semelhante à narrativa feita pelo Barão de Gerando, ainda no século XIX: crianças oriundas do abandono e da miséria são tratadas como filhos, educadas e recebem bens de seus pais adotivos. (Weber, 2001).

$\mathrm{Na}$ sociedade luso-brasileira de fins do século XVIII e início do XIX, a ausência de prole biológica também era vista como um dos principais incentivos à adoção. No ano de 1789, por exemplo, membros do Tribunal do Desembargo do Paço de Lisboa - órgão responsável pela análise dos pedidos de adoção provenientes de todo o Império Português - sintetizavam a opinião de juristas e legisladores portugueses do período ao argumentarem que as adoções haviam sido "(...) introduzidas pelo Direito Civil dos Romanos para a consolação dos que não tem filhos...". 3 Justificativa que os próprios interessados em adotar acabavam incorporando em seus requerimentos, conforme observamos em um pedido feito no ano de 1792: “(...) por suavizar o sentimento de falta de filho desejava adrogar ou perfilhar ficando a menor legitimada como filha...". ${ }^{4}$

Do ponto de vista legislativo, a ausência de filhos como incentivo à adoção estava ligada à tradição jurídica romana, onde a incorporação de filhos alheios era utilizada para garantir a perpetuação do culto doméstico, o nome e as tradições familiares de indivíduos sem descendentes. No Direito Romano clássico, essa incorporação era feita por meio da "adrogação" e da "adoção". Lembrando que a família no código romano dizia respeito a um grupo de pessoas subordinadas ao domínio de um pater familias, e não a membros unidos por laços de sangue ou 
ADOÇÃO: PRÁTICAS JURÍDICAS E SOCIAIS...

de matrimônio, destacamos que essas duas formas de incorporação eram delimitadas em função da existência, ou não, de pátrio poder sobre a pessoa a ser incorporada. O primeiro tipo dizia respeito aos sui iuris, ou seja, os que não estavam subordinados a nenhum pater familias ou eram eles próprios pater acarretando, nesse caso, a passagem de toda a família do adotado para o pátrio poder do adotante. A segunda forma era utilizada nos casos de alieni iuri, onde o pátrio poder era transferido de uma pessoa, geralmente o pai, para o adotante. Nesse universo, as regras em torno da adrogação e da adoção seguiam as mesmas prerrogativas impostas ao pater familias, sendo, portanto, vedada aos que não podiam exercer tal direito: os filhos familias e as mulheres. (BOSWELL, 1984:10-33 e 1988: 389, 244; COSTA, 1969: 9-12; CRUZ, 1938: 1-72; GAGER, 1996: cap. 2 e MAHILLON, 1962: 435-57).

Foi com o avançar do Cristianismo que surgiram modificações na adoção romana tradicional, as quais estavam intimamente ligadas às mudanças ocorridas no próprio conceito de família. A partir do momento em que a Igreja católica e as autoridades civis passaram a definir a supremacia dos laços sangüíneos de filiação e do matrimônio sacramentado como os legítimos constituintes da unidade familiar, a adoção adquiriu o objetivo de criar artificialmente os laços de filiação. Para tanto, a adrogação e a adoção precisavam imitar as leis da natureza surgindo exigências em torno de diferenças de idade entre adotantes e adotados, a proibição de praticá-la aos incapazes de procriar e o interdito dos pais adotarem filhos ilegítimos. Nesse período também apareceram duas outras modalidades: a adoptio plena, que servia para a incorporação de parentes com uma efetiva mudança de família, e a adoption minus plena voltada à incorporação de estranhos, os quais preservavam suas relações familiares originais. Apesar das regulamentações, o bacharel Paulo Merêa argumentou que as diferenciações entre adoptio plena e adoption minus plena não tiveram uma aplicação efetiva na sociedade portuguesa. Pesquisando documentos medievais referentes à adoção, o autor não identificou distinções entre adrogação e adoção. (COSTA, 1969: 9-12 e MERÊA, 1956 b: 186). 
Para a Península Ibérica, as prerrogativas em torno da adoção também foram percebidas nas fontes históricas do período medieval. Segundo o bacharel Guilherme Cruz: “(...) $\mathrm{Na}$ segunda metade do século XIII, as Siete Partidas de Afonso X, muito influenciadas já pelo renascimento do direito romano, recorreram às palavras porfijar e porfijamiento para designar o mesmo instituto a que os romanos chamavam adoptio". Foi também no decurso daquele século que o instituto passou por redefinições essenciais. Dentre elas, a mais crucial foi a ênfase dada ao aspecto patrimonial da adoção, fazendo com que os adotados passassem a ser considerados "filhos legítimos". Porém, conforme os argumentos de Cruz, os perfilhados não adquiriam todos os direitos e deveres dos filhos biológicos, mas apenas os que eram expressamente indicados nos documentos de perfilhação. Por isso, o perfilhado mantinha os laços familiares de origem, não eram criadas quaisquer ligações com os parentes do perfilhador e nem surgiam impedimentos matrimoniais entre perfilhados e filhos biológicos, como ocorria na adoção presente no código romano clássico. Devido ao seu caráter patrimonial, a perfilhação seguia as regras da doação de bens. (CRUZ, 1938: 1-72, MEREAA, 1956 b: 182-94). ${ }^{5}$

Segundo o bacharel Paulo Merêa, nas Ordenações Filipinas copiladas no início do século XVII: “(...) o perfilhamento era sempre a adopção do direito romano como arrogação, isto é, a adopção de uma pessoa sui iuris" (MERÊA, 1956 b: 192). Essas leis apenas tangenciaram a prática determinando que o Tribunal do Desembargo do Paço de Lisboa era responsável pelas confirmações de adoções, que os filhos adotivos não herdavam os bens da Coroa e que eles não podiam ser citados no lugar dos pais adotivos envolvidos em causas judiciais. Juristas dos séculos XVI ao XIX foram unânimes em afirmar que essa quase omissão da lei pátria ocorria pelo completo desuso do instituto no período. Elaborando um compêndio sobre direito civil português em fins do XVIII, Pascoal José de Melo Freire afirmava que havia a adrogação e a adoção, mas que: "(...) Todavia, de nenhuma delas temos de tratar aqui, visto que não estão em uso, conforme testemunha Cabedo". ${ }^{6}$ Jorge de Cabedo 
foi um importante jurisconsulto do século XVI, o qual não estava sozinho em suas afirmações. Um outro proeminente jurista da época, Álvaro Vaz (Valasco), reiterava essa raridade ao afirmar que tinha conhecimento de um único caso de adoção ao longo de todo o período quinhentista português. (MEREAA, 1956 b: 119-20 e SILVA, 1985: 332-3, partes II e III).

Declarações como estas e a falta de uma normatização sistemática na legislação de Portugal e do Brasil levou os estudiosos do século XX a reiterar a ausência da adoção nos três séculos precedentes. O bacharel português Mário Costa declarou que: “(...) desde a segunda metade do século XVII, a adoção perdeu todo o seu alcance prático, para mais tarde desaparecer mesmo da exposição teórica dos autores. O Código de 1867 omitiu-a inteiramente". Por sua vez, a historiadora Isabel Sá foi taxativa: "Não existe legislação em Portugal referente à adoção de crianças no séc. XVIII". Entre os historiadores brasileiros, Maria Luiza Marcílio ressaltou: “(...) sem o estatuto da adoção - que surgiu na legislação brasileira apenas no século XX - só se podia adotar uma criança informalmente, como filhos de criação sem direito à sucessão". (COSTA, 1969: 28; SÁ, 1995: 87 e MARCILIO, 1998: 301).

Situação semelhante foi identificada pela historiadora Kristin Gager para a sociedade francesa, entre os séculos XVI e XVII. Em escritos de juristas, literatos e religiosos - católicos e protestantes -, a adoção era considerada inexistente e desaconselhada por ser antinatural e anticristã. Segundo os autores analisados por Gager, as pessoas podiam desvirtuar as características originais da adoção (dar filhos a casais estéreis) e tentar introduzir no seio da família legalizada crianças oriundas de relações ilegítimas. Por sua vez, as próprias famílias tinham razões para não adotar: a relutância em assumir publicamente a esterilidade (associada à bruxaria e ao castigo pelos pecados); as pressões da parentela sanguínea (herdeiros forçados na ausência de descendentes); cuidados em torno da linhagem e da pureza de sangue familiar (contrários à inclusão de estranhos) e, por fim, temores de se adotar algum parente abandonado anonimamente, o qual podia gerar incestos futuros ao se casar 
na parentela (tema tão comum na literatura desde a Antiguidade e a clássica lenda de Édipo Rei) ${ }^{7}$. Restrições legislativas e sociais que levaram os historiadores da família a sustentar que a adoção não era praticada na França até o final do século XIX. Práticas regionais identificadas por Paul Gonnet (1935) e por Jacqueline Roubert (1978), destacando a corriqueira adoção de órfãos assistidos pelas instituições de Lyon, nos séculos XVI e XVII, foram consideradas exceções pela historiografia francesa. (GAGER, 1996: 1-5 e cap. 1).

Convencida de que os interesses das instituições em transferir à sociedade a responsabilidade sobre centenas de crianças abandonadas poderiam se aproximar dos interesses de casais sem filhos - que buscavam a transmissão de suas tradições familiares, de seus nomes e mesmo dos bens -, Kristin Gager procurou indícios da prática da adoção em outras localidades francesas. Esses indícios foram encontrados em escritos literários: de Montaigne nomeando Mademoseile Maria le Jars de Gournay como fille d'alliance passando por Louise Bourgeois que se intitulava adopted daughter. Também foram identificados em textos jurídicos: o Código Civil de 1804 mantinha a adoção, embora restrita aos casais acima de 50 anos e sem filhos legítimos. Aprofundando suas pesquisas, Gager acabou confirmando que a prática da adoção também ocorria em Paris do início da Modernidade: os livros cartoriais dos tabeliães locais testemunhavam a existência de contratos de adoção envolvendo crianças órfãs, expostas e desvalidas. (GAGER, 1996: $5-9$, caps. 3 e 5$)$. ${ }^{8}$

De maneira geral, podemos identificar uma periodização entre os especialistas em torno da prática da adoção: do período romano ao século XVI, o mais tardar meados do XVII, o instituto passou por um momento de apogeu, declínio e extinção para retornar no século XX em diferentes códigos civis do mundo todo. Ao longo de quase três séculos, a adoção parece ter ficado adormecida esperando por seu "retorno triunfal", particularmente, após a segunda guerra e diante de um contexto de orfandade generalizada na Europa. Como ressaltou o historiador brasileiro Renato Venâncio, os estudiosos europeus 
ADOÇÃO: PRÁTICAS JURÍDICAS E SOCIAIS...

concordam com esse "eclipse" da adoção, vinculando-o a três aspectos principais: a ênfase medieval nas linhagens sanguíneas, a valorização dos padrinhos como pais adotivos informais e o interesse de instituições religiosas na apropriação de bens oriundos de indivíduos sem descendentes. (VENÂNCIO, 2005: 271-2). ${ }^{9}$

Porém, como salientou Kristin Gager, a insistência de juristas, literatos e mesmo de religiosos na pouca expressividade da adoção na Europa e em seus domínios nos séculos anteriores ao $\mathrm{XX}$ deve ser vista com cautela, pois as leis não têm um caráter estático: elas eram - e continuam sendo - interpretadas e reinterpretadas pela prática social. Nesse sentido, a inexistência de legislação luso-brasileira, até o século XX, acerca do instituto da adoção, pode nos informar muito mais sobre as expectativas dos juristas e da elite intelectual em torno da valorização de um modelo familiar e de transmissão de bens, via laços consangüíneos, do que comprovar a ausência da prática da adoção. Diante da omissão de leis nacionais, as pessoas podiam buscar caminhos alternativos que oferecessem a crianças e jovens, "criados em conta de filho", os mesmos direitos atribuídos aos filhos sangüíneos.

Impulsionados por estas premissas, procuramos fontes que nos permitissem avaliar a prática da adoção legalizada no Império luso-brasileiro. Pesquisando a documentação do Tribunal do Desembargo do Paço de Lisboa e das Chancelarias Régias (fundos sob a guarda do Arquivo Nacional da Torre do Tombo/Lisboa), pudemos identificar fontes inéditas na historiografia portuguesa e brasileira relativas à temática: cartas de adoção e processos cíveis de adoção. ${ }^{10}$

\section{De filhos alheios a filhos legítimos: práticas sociais em torno da adoção.}

Por meio da análise das cartas e dos processos de adoção, percebemos que o direito romano servia de alicerce aos súditos portugueses e brasileiros que desejavam incorporar filhos 
alheios de forma legalizada, em fins do século XVIII e início do XIX. Apesar disso, os propósitos da adoção em Roma e nas sociedades do Antigo Regime acabaram se afastando em certos aspectos: enquanto que entre os romanos a prioridade era dar continuidade ao culto religioso doméstico, no segundo caso, as questões patrimoniais se tornavam essenciais. Característica histórica enraizada no século XII, a transmissão de bens foi vista por alguns juristas portugueses como a principal função da adoção legalizada praticada no período anterior ao século XX. No final da década de 1930, o bacharel Guilherme Cruz chegou a fazer a seguinte afirmação: “(...) o vínculo que a perfilatio fazia surgir era apenas um meio de que se lançava mão para obter um determinado efeito patrimonial". (CRUZ, 1938: 16)

De fato, a adoção formal garantia aos filhos adotivos os mesmos direitos dos sangüíneos e legítimos: a sucessão nos bens paternos e maternos, abintestado ou não. No caso da existência de filhos biológicos e adotados, a legislação previa que ambos herdavam em igualdade de condições. Ao analisarmos as cartas e processos de adoção julgados pelo Tribunal do Desembargo do Paço de Lisboa, entre 1765 e 1822, percebemos que a totalidade dos adotantes não possuía descendente fazendo com que os filhos adotivos fossem os únicos beneficiados. Pelas palavras de um capitão morador em Lisboa, pudemos identificar a íntima ligação entre adoção e transmissão de bens: “(...) pelo instrumento junto a adotou por sua filha para lhe poder suceder em todos os seus bens e honras como se sua filha legítima e natural fosse..." 11

Ainda que a falta de descendentes entre os adotantes fosse uma característica das fontes analisadas, isso não significava que inexistiam herdeiros forçados. Segundo as Ordenações Filipinas, parentes sanguíneos, ascendentes ou colaterais, recebiam os bens em casos de falecimento de indivíduos abintestado e sem descendentes, legítimos ou legitimados ${ }^{12}$. Por isso, em casos da presença de herdeiros forçados, os processos de adoção continham inquirições feitas pelos Corregedores Cíveis junto aos eventuais parentes beneficiados. Nessas inquirições, eles declaravam se 
concordavam, ou não, com a adoção, a qual significava, em última instância, a perda dos bens. Indicando a existência de possíveis negociações anteriores, a imensa maioria das fontes analisadas trazia a concordância desses eventuais herdeiros, os quais deviam assinar um Termo de Consentimento. Foi assim no ano de 1776, quando as duas irmãs de D. Thereza de Mello Carrolas declararam que: “(...) como mais próximas parentas não tinham dúvida no requerimento de adoção e nele consentiam...". 13

O único caso em que identificamos objeção, ela ocorreu de maneira indireta. Estando ausente um sobrinho da adotante e existindo dois outros menores, o curador deles, Manoel Pinheiro, se mostrou contrário à adoção da garota Maria Roza: “(...) por tirar aos legítimos e consangüíneos sucessores a dita sucessão...". Por meio desse depoimento, percebemos um dos principais entraves jurídicos que dificultava a prática da adoção: o sistema de sucessão sanguínea. Conforme salientou a historiadora Kristin Gager para a França quinhentista, a legislação e os autores franceses insistiam em valorizar os laços sangüíneos como únicos elos de ligação familiar e, conseqüente, única via de acesso aos bens. Ao possibilitar que indivíduos estranhos partilhassem ou mesmo monopolizassem esses bens, a adoção era vista por muitos como um instrumento contrário às leis, fossem naturais ou civis. Foi nesse sentido que o curador Manoel Pinheiro construiu a sua argumentação. Citando vários juristas e as Ordenações Filipinas, Pinheiro defendia que a adoção retirava os bens dos parentes consangüíneos - como legítimos herdeiros - favorecendo pessoas estranhas: “(...) Esta pode ser a razão porque Barbosa, ad. Ord. Livro 2, t. 3 , § 1, n $\mathrm{n}^{\circ}$, com Cabed. p 2, dubit 70, $\mathrm{n}^{\circ} 4$ afirma que neste Reino se não costumam conceder confirmações de semelhante perfilhamento..." ${ }^{14}$. As palavras de Pinheiro enfatizam a hipótese de Kristin Gager de que a inexistência de normas jurídicas referentes à adoção era uma tentativa de moldar a prática social desinformando e desestimulando a formação de famílias unidas por laços não sangüíneos. (GAGER, 1996: 81). 
$\mathrm{Na}$ verdade, os argumentos de Manoel Pinheiro não foram suficientes para impugnar a adoção de Maria Roza. Se os laços consangüíneos garantiam a participação dos parentes como herdeiros, não havia problemas, pois ela era sobrinha materna de sua mãe adotiva. Nesse caso, a adoção reforçava os laços de parentesco previamente existentes. A questão era que Maria Roza possuía três irmãos, os quais reivindicavam participação igualitária na herança dos tios. Além deles, havia ainda cerca de duas dezenas de outros parentes colaterais dos pais adotivos que foram ouvidos pelo Corregedor Cível e concordaram com a adoção. Entre eles estava a própria mãe biológica da garota que, na condição de irmã da adotante, tinha prioridade entre os herdeiros. Porém, ela desistiu dos direitos sobre a herança em benefício da filha. Segundo suas declarações: “(...) consentia na perfilhação que suplicantes pretendiam fazer à dita sua filha e prestava todo o seu consentimento". No momento da adoção, e mesmo quando entregou a filha para ser criada pela irmã e pelo cunhado, essa mulher podia estar vivenciando estratégias de sobrevivência que visavam melhores condições de vida para a garota. Situação semelhante pode ser percebida em um outro processo de adoção ocorrido no ano de 1792, quando os pais e outros herdeiros forçados declararam que: “(...) todos | herdeiros | convinham na perfilhação da dita menor, como também os pais da menina...". ${ }^{15}$

Nos casos acima, percebemos a importância do consentimento dos pais biológicos para que a adoção pudesse ser efetivada. Além das questões patrimoniais, devemos lembrar a influência do direito romano, no qual a adoção girava em torno do exercício do pátrio poder: ou um filho família passava do poder de um pater para outro ou alguém isento de domínio paterno passava a viver sob o pátrio poder do adotante. Portanto, a adoção instaurava um pátrio poder, anulando a atuação do pai biológico. Porém, a concordância dos pais naturais, expressa em parte da documentação analisada, não implicava a perda da origem biológica do perfilhado. Segundo o jurisconsulto oitocentista Manoel Borges Carneiro, as relações originais eram mantidas no tocante à sucessão, podendo o filho 
ADOÇÃO: PRÁTICAS JURÍDICAS E SOCIAIS...

herdar abintestado tanto ao pai adotivo quanto ao biológico. Acepções confirmadas por um dos Corregedores Cíveis da cidade de Lisboa, em 1822, ao apresentar o seguinte parecer: “(...) sem que a adrogada, pelo fato da adrogação perca os direitos que lhe competirem a respeito dos que tiveram seus legítimos e verdadeiros pais, convenho na pretensão dos suplicantes". ${ }^{16}$

Pudemos perceber, então, que os objetivos patrimoniais das cartas de adoção, primordialmente enfatizados pela bibliografia, não eram as únicas funções desse instrumento jurídico. Perpassando questões relacionadas ao pátrio poder, identificamos até casos em que a prioridade da carta de adoção era a obtenção de pátrio poder sobre o adotado, sendo a transmissão de bens um aspecto secundário. Em 1819, a perfilhação de uma exposta da Santa Casa de Misericórdia de Lisboa gerou um conflito entre a mãe adotiva e o mordomo da instituição, exatamente, em torno do direito de exercício do pátrio poder. Aos dois anos de idade, a enjeitada Eduarda foi entregue pela Santa para ser criada gratuitamente por D. Francisca de Paula. Naquele ano, a menina estava com seis anos e foi retirada dos cuidados de D. Francisca por esta ser acusada de manter uma casa de prostituição na corte. Após várias tentativas frustradas de recuperar Eduarda, D. Francisca registrou uma escritura de adoção da menina e iniciou o processo cível para conseguir a confirmação régia. Provavelmente, a atitude de D. Francisca foi aconselhada e incentivada por seus amigos pessoais que testemunharam em seu favor no processo cível conduzido pelo Corregedor de Lisboa: um fidalgo do rei, um procurador cível e cavaleiro da Ordem de Cristo e um fidalgo negociante, o qual devia ser o mais íntimo desses amigos pois além de depor no processo, foi testemunha na escritura de adoção e era procurador de D. Francisca. Amparada por essas relações de amizade, ela conseguiu a carta de adoção de Eduarda alguns meses depois. No documento aparecia a expressa condição de que: “(...) adotava a referida menina por sua filha a fim de gozar de todas as prerrogativas como se legitimamente descendesse dela 
outorgante com tal condição de se lhe entregar, para continuar na sua educação desligando-se do poder da dita Santa Casa da Misericórdia para ficar sujeita a seu maternal poder e administração havendo para esse fim como sua tutora e curadora..." 17

Após a carta de adoção ter sido registrada na Chancelaria Régia, D. Francisca foi até a Santa Casa buscar a menina, mas o mordomo negou-se a entregá-la. Em um requerimento enviado ao Tribunal do Desembargo para justificar sua atitude, ele argumentava que a adoção: “(...) não mudara a condição de exposta de Eduarda". Continuando seu argumento, o mordomo enfatizava que ela permanecia sob seu pátrio poder, uma vez que o cargo dele: “(...) representa ser Pai de tão numerosa família; o que assim se pratica a ponto de se não poderem casar nem emancipar sem licença minha por escrito...". Tal responsabilidade sobre os expostos era enfatizada por autores oitocentistas portugueses que se dedicaram ao tema da assistência aos expostos, como João da Veiga: (...) os expostos se não tem pais legítimos, têm por pais adotivos os Nobres administradores das Rodas; (um fidalgo da primeira nobreza costumava ser administrador da Roda de Lisboa) ...". ${ }^{18}$

De fato, o mordomo do caso analisado era o Marquês de Abrantes que procurava exercer o pátrio poder em relação aos expostos atendidos pela Santa Casa de Misericórdia. Essa função era reafirmada pelo próprio monarca, podendo ser observada, tanto nas palavras acima do Marquês de Abrantes, quanto em um outro tipo de documentação relacionada à Santa Casa de Lisboa que eram os requerimentos de emancipação solicitados por expostas atendidas pela instituição. Intitulandose "filha da Real Casa dos Expostos", toda enjeitada precisava da "licença e autorização" da Misericórdia para concorrer aos sorteios anuais de dotes, emancipar-se ou casar-se, como podemos ver no seguinte requerimento: "Diz Luiza de Jesus, filha da Real Casa dos Expostos, que tendo 29 anos e requerendo de Vossa Alteza Real provisão de Emancipação por estar nas circunstâncias da Lei, foi Sua Alteza Real servido mandasse juntar consentimento da Santa Casa..." 19 
ADOÇÃO: PRÁTICAS JURÍDICAS E SOCIAIS...

Apesar destas premissas, de acordo com o universo mental das mercês, o monarca podia conceder exceções às regras. No caso da adoção da enjeitada Eduarda, os relacionamentos pessoais de D. Francisca - conseguidos ou não por seus amigos freqüentarem sua alcovitice de luxo - podem ter sido fundamentais no processo de confirmação régia da adoção e, conseqüentemente, da destituição de qualquer autoridade que a Santa Casa pudesse exercer em relação à menina. Pela carta, D. Francisca passava à condição de tutora de Eduarda significando, na prática, que a menina ficaria sobre os cuidados e poder dela. Emitindo ordens expressas para que o mordomo cumprisse a carta de adoção e entregasse a garota para a mãe adotiva, os Desembargadores do Paço de Lisboa nos permitem identificar questões relacionadas à prática da adoção legalizada na sociedade luso-brasileira que ultrapassam os aspectos patrimoniais.

Ao analisarmos a prática da adoção legalizada na sociedade luso-brasileira de fins do século XVIII e início do XIX, percebemos que as práticas de transmissão de bens não se limitavam ao universo sanguíneo. Apesar disso, pais e mães adotivos viviam em uma sociedade que privilegiava esses mesmos laços sangüíneos na sucessão dos bens. Por isso, eles precisavam buscar caminhos alternativos que garantissem aos filhos alheios acolhidos e criados "em conta de filho" os direitos inerentes à prole biológica. Tais caminhos acabaram levando ao direito romano que lhes forneceu o alicerce e o instrumento jurídico necessário: as cartas de adoção. Revelando o ápice de um relacionamento familiar iniciado com o acolhimento de crianças órfãs, abandonadas ou filhas de parentes próximos ou amigos, a adoção legalizada representava uma das possibilidades de incorporação sociofamiliar de filhos alheios no período. Outras existiam e ainda existem. Cabe aos estudiosos a tarefa de identificá-las e analisá-las, pois, como nos lembra Robert Darnton no prefácio de Boemia Literária e Revolução, "Reconstruir mundos é uma das tarefas essenciais do historiador". 


\section{Referências Bibliográficas}

AlexandRe-Bidon, D. e LeTt, D., (org.), Les enfants au Moyen Age - $V^{e}$ siècles, Paris: Ed. Hachette, 1997;

BoswelL, J., Expositio and Oblatio: The Abandonment of Children and the Ancient and Medieval Family. In The American Historical Review, vol. 89, $\mathrm{n}^{\circ} 1$, pp. 10-33, 1984.

La misericórdia Ajena (1988), trad. Marco A. Galmarini, Barcelona: Muchnick Ed., 1999;

Costa, M. J. A., A adopção na História do Direito Português. In Separata da Revista Portuguesa de História,Coimbra, tomo 12, 1969, pp. 95-120;

CRUZ, G. B., Algumas considerações sobre a perfilatio. In Separata do Boletim da Faculdade de Direito, Coimbra, vol. 14, pp. 1-72, 1938;

GAGER, K. E., Blood Ties and Fictive Tiés: adoption and family life in Early Modern France, Princeton: Princeton University Press, 1996;

GONNET, P., L'adoption lyonnaise des orphelins légitimes (1536-1793), 2 vol., Paris, 1935;

Goody, J., Família e casamento na Europa, Oeiras: Celta Editora, 1995;

GuTTON, J. P., Histoire de l' adoption en France, Paris: Publisud, 1993;

LONDOÑo, F. T., A origem do conceito menor. In DEL PRIORE, M. (org.), História da criança no Brasil, São Paulo: Editora Contexto, 1991;

MAHILLON, P., Evolution historique de l'adoption depuis le droit romain. In En Hommage a Victor Gothot, Liège, pp. 435-57, 1962;

MARCilio, M. L., História Social da Criança Abandonada, São Paulo: Hucitec, 1998;

MARTINS, J. S., (org.), O massacre dos inocentes: a criança sem infância no Brasil, São Paulo: Hucitec, 1991;

MeRÊA, M. P., Sobre a adopção no século XII. In Boletim da Faculdade de Direito, Coimbra, vol. 31, pp. 372-6, 1955;

, Perfilhação - achega para um dicionário histórico da

Língua Portuguesa. In Separata da Revista Portuguesa de Filologia, Coimbra, vol. 7, pp. 118-27, 1956 a;

, Sinopse Histórica da adoção (perfilhamento). In Boletim da Faculdade de Direito, Coimbra, vol. 32, pp. 132-94, 1956 b;

ROUBERT, J., L'adoption des enfants par des particuliers à Lyon sous l'ancien régime. In Société française d'histoire des hôpitaux, Paris, vol. 36-37, pp. 3-30, 1978;

SÁ, I. G., A circulação de crianças na Europa do Sul: O caso dos expostos do Porto no século XVIII, Lisboa: Fundação Calouste Gulbenkian, 1995; 
ADOÇÃO: PRÁTICAS JURÍDICAS E SOCIAIS...

Silva, N. J., História do Direito Português: fontes de direito, Lisboa: Fundação Calouste Gulbenkian, 1985;

VEnÂNCIO, R. P., Famílias abandonadas: a Assistência à criança de camadas populares no Rio de Janeiro e em Salvador - séculos XVIII e XIX, Campinas: Papirus, 1999;

, Adoção antes de 1916. In LEITE, E., (coord.), Adoção: aspectos jurídicos e metajurídicos, Rio de Janeiro: Ed. Forense, 2005, pp. 271-82;

WEBER, L. N. D., Pais e filhos por adoção no Brasil: características, expectativas e sentimentos, Curitiba: Juruá, 2001.

MORENO, Alessandra Zorzetto. Adoption: Legal and Social Practices in Luso-Brazilian Empire (XVIII-XIX). História, v.28, n.2, p.449-466, 2009.

\begin{abstract}
In this article, first, we performed a history of legal interpretations and historiographical around the theme of the adoption in Luso-Brazilian society, in the period prior to the twentieth century. Next, we analyzed unpublished documentation in historiography represented by letters and adoption processes for understanding the social practices of familial incorporation of someone else's children.
\end{abstract}

Keywords: Adoption; Luso-Brazilian legislation; Transfer of property; Roman law.

\title{
NOTAS
}

${ }^{1}$ Este artigo foi baseado em minha tese de doutorado, defendida no Instituto de Filosofia e Ciências Humanas da Universidade Estadual de Campinas (IFCH/UNICAMP), financiada pela FAPESP e intitulada "Vivendo em lares alheios: acolhimento domiciliar, criação e adoção na cidade de São Paulo (1765-1822)", 2007. Disponível em: http://libdigi.unicamp.br. Acesso 12 dez. 2007.

${ }^{2}$ Até pelos menos o fim do século XVIII, as palavras "enjeitado" e "exposto" eram utilizadas para designar os meninos e meninas cujos 
pais biológicos não podiam, ou não desejavam, mantê-los junto a si. A expressão "criança abandonada" começou a ser utilizada somente a partir do início do século XIX, tornando-se comum a partir de então. Ver, entre outros: VENÂNCIO, 1999: 18-23, LONDOÑO, 1991: 129-45 e os vários artigos em MARTINS, J. S., 1991.

3 Arquivo Nacional da Torre do Tombo, Desembargo do Paço, Repartição Corte, Estremadura e Ilhas, Maço 2122, caixa 1956, doc. 34, Autos Cíveis de Requerimento de João Bento Pithon (1789). Daqui em diante ANTT, DP e RCEI, respectivamente. As Ordenações Filipinas, Lisboa: Fundação Calouste Gulbenkian, 1985 (reimpressão fac-similiar de 1870), Livro 3, tit. 64 declaravam que os casos omissos deviam ser tratados pela legislação romana. Essa utilização se tornou tão freqüente que, em meados do século XVIII, um movimento jurídico procurou recolocar o direito romano na condição de "legislação subsidiária", particularmente, por meio da Lei da Boa Razão de 18/8/1769. Ver: SILVA, N. J., 1985: especialmente a parte II e III; MEREAA, M. P., 1955: 372-6 e SÁ, I. G., 1995: 75-86.

${ }^{4}$ ANTT, Chancelaria de D. João VI, Livro 4 de Perdões e Legitimações, fl. 6 v., Carta de Adoção de Maria Joaquina do Céu (1792).

${ }^{5}$ Novas modificações no uso do perfilhamento ocorreram ao longo do século XVIII. A partir de então, o conceito se aproximou de uma prática de incorporação de filhos ilegítimos, de maneira bem semelhante às legitimações. No século $X X$, o termo perdeu qualquer ligação com a adoção de estranhos passando a designar somente os ilegítimos reconhecidos. (MERÊA, 1956 a: 118-27).

${ }^{6}$ P. J. M. Freire, Instituições de Direito Civil Português (1794), Livro 2, tit. 6, § 9. In Boletins do Ministério da Justiça de Portugal, 1966-1967. Disponível em http://www.iuslusitaniae.fcsh.unl.pt. Acesso em 20 ago. 2006. Sobre a adoção nas ordenações, ver: Ordenações Filipinas, op. cit., Livro 1, tit. 3, § 1; Livro 2, tit. 35, § 12; tit. 56, preâmbulo, tit. 9, § 2.

${ }^{7}$ Para uma análise dos contos envolvendo expostos e abandonados, ver: BOSWELL, 1999: 25-8, 114-121 e 142-9. Sobre a esterilidade como um pecado e a fecundidade como uma graça divina na tradição cristã, ver: ALEXANDRE-BIDON e LETT, 1997: 24-6.

${ }^{8}$ Os contratos de adoção analisados pela autora eram feitos de duas maneiras: entre os administradores das instituições de assistência e os pais adotivos; entre pais biológicos e adotivos.

9 Os três aspectos citados foram elaborados, respectivamente, por Gager (1996), GUTTON, (1993) e GOODY (1995). 
ADOÇÃO: PRÁTICAS JURÍDICAS E SOCIAIS...

${ }^{10}$ As cartas de adoção fazem parte da documentação das Chancelarias Régias, tendo sido registradas nos Livros de Legitimação e Perdão ou nos Livros de Ofícios e Mercês. No caso dos moradores no Ultramar, além dos livros das Chancelarias, as cartas também eram registradas nos códices de Registros de Ofícios do Conselho Ultramarino (sob guarda do Arquivo Histórico Ultramarino/Lisboa). A Carta de Adoção era o último passo de um processo iniciado junto ao Corregedor Cível de cada Comarca judiciária: os processos cíveis de adoção, que formam o outro conjunto de fontes que analisamos e estão arquivados no fundo do Tribunal do Desembargo do Paço de Lisboa. O processo era composto por várias partes: um requerimento resumindo os motivos da adoção; uma escritura pública de adoção (a qual também podia ser intitulada como "perfilhação", "adrogação" ou ainda "adrogação e filiação"); um rol de testemunhas que confirmavam a veracidade das informações contidas nas escrituras (tais como convivência e tratamento familiar entre adotantes e adotados, fornecimento de alimentos, roupas e educação por parte dos adotantes, etc); declarações de concordância de eventuais herdeiros forçados, e, por fim, o despacho do Corregedor. Esse processo era enviado ao Tribunal do Desembargado do Paço que elaborava o seu parecer. Os pedidos deferidos eram enviados para a confirmação régia, a qual era feita por meio do registro da carta de adoção nos livros das Chancelarias Régias.

11 ANTT, DP/RCEI, maço 284, caixa 269, doc. 42, Autos Cíveis de Requerimento de Manoel Rodrigues de Souza Cabral (1807).

${ }^{12}$ Ordenações Filipinas, op. cit., Livro 1, tit. 88; Livro 4, tits. 46, 81 (nota 3) e 91, Aditamentos, Lei de 9 de setembro de 1769; Manoel B. Carneiro, Direito Civil de Portugal contendo três livros, (1826), Lisboa: Typographia de Antonio José da Rocha, 1851, Livro 2, tit. 23, § 211, alínea 1.

${ }^{13}$ ANTT, DP/RCEI, maço 1332, caixa 1143 , doc. s/nº, Autos Cíveis de Requerimento de D. Thereza de Mello Carrolas (1776).

${ }_{14}$ ANTT, DP/RCEI, maço 1388, caixa 1192, doc. 14, Autos Cíveis de Requerimento de Joaquim José Gil e Faustina Maria (1788).

${ }_{15}$ ANTT, DP/RCEI, maço 1388, caixa 1192, doc. 14, Autos Cíveis de Requerimento de Joaquim José Gil e Faustina Maria (1788); Chancelaria de D. João VI, Livro 14 de Registro de Legitimações e Perdões, fl. 6 v., Carta de Adoção de Maria Joaquina do Céu (1792). 
${ }^{16}$ Manoel B. Carneiro, Direito Civil.., op. cit., Livro 1, tit. 23, § 211, alíneas 1 e 2; ANTT, DP/RCEI, maço 335, doc. 2, Autos Cíveis de Requerimento de João Barga e Maria Garcia (1822).

${ }^{17}$ ANTT, DP/RCEI, maço 312, doc. 35, Autos Cíveis de Requerimento de D. Francisca de Paula (1819); Chancelaria de D. João VI, Livro n ${ }^{\circ} 5$ de Legitimações e Perdões, fl. 374, Carta de Adoção de Eduarda (1820).

${ }^{18}$ Idem; J. C. Veiga, Reflexões ou Breve Discurso sobre as Rodas dos Expostos, Coimbra, Imprensa a Universidade, 1853, p. 14.

${ }^{19}$ ANTT, DP/RCEI, maço 287, caixa 272, doc. 17 (1811), grifos nossos.

Artigo recebido em 04/2009. Aprovado em 10/2009. 